\title{
LÓGICA E COMPOSIÇÃO DOS ORDENAMENTOS JURÍDICOS
}

Maria Francisca Carneiro*

SUMÁRIO: 1. Aproximações entre Lógica, Direito e Justiça. 2. Projeçôes sobre a composição dos ordenamentos jứdicos. 3. Conclusão. 4. Bibliografia.

SUMMARY: 1. Approaches between Logic, Law and Justice. 2. Projections on the composition of the legal systems. 3. Conclusion. 4. Bibliography.

SUMARIO: 1. Se acerca entre la lógica, la derecha y la justicia. 2. Proyecciones en la composición de los sistemas legislativos. 3. Conclusion. 4. Bibliografia.

RESUMO: Trata-se de interesses e origens comuns ao Direito e à Lógica, numa abordagem histórica, comentando-se também algumas discrepâncias verificadas em determinados momentos do desenvolvimento desses saberes. Delineia-se um panorama geral de algumas das modernas concepcóes teóncas dos ordenamentos juridicos e seus modelos, refletindo-se sobre as suas possibilidades de investigação, em face dos avanços da Lógica na atualidadc. A linguagem é simples, procurando-se evitar eventuais hermetismos decorrentes do uso excessivo de termos técnicos, para facilitar a comunicação entre diferentes áreas do conhecimento. Junto são apostas indicaçóes bibliográficas, visando subsidiar as consultas pelos interessados no assunto.

ABSTRACT: This text is about interests and common onigins to the Law and the Logic, in a historical boarding, commenting also some discrepancics verified in determined moments of the development of these knowledges. It is delineated a general panorama of some of the modern theoretical conceptions of legal systems and its models, reflecting itself on its possibilities of inquiry, in face of Logic advances in the present time. The language is simple, looking itself to prevent eventual decurrent hermetisms of extreme use of technical terms to facilitate communication between different areas of lanowledge. Together it is pointed bibliographical indications, aiming to subsidize the consultations for the interested parties in the subject.

" Doutora en Direito, mestra en Educacão e bacharela en Filosofra. Professora na Universidade federal do Pana. 
RESUMEN: Esto texto es sobre los intereses y origenes comunes a lo derecho y a la lógica, en un abordaje histórico, comentando también algunas discrepancias verificadas en los momentos resueltos del desarrollo de éstos para saber. Se delinea también un panorama general de algunos de los conceptos teóricos modernos de los sistemas legislativos y de sus modelos, reflejandose en sus posibilidades de investigación, en la cara de los avances de la lógica en el actual tiempo. La lengua es simple, mirándose para prevenir hermetismos decurrentes del eventual uso extremo de los los términos técnicos, de facilitar la comunicación entre diversas áreas del conocimiento. Juntas son apostas indicaciones bibliográficas, teniendo como objetivo subvencionar las consultas para los interesados en el tema.

PALAVRAS CHAVE: Lógica. Composiçăo. Direito. Justiça. Ordenamento jurídico.

KEY-WORDS: Logic. Composition. Right, Justice. Legal system.

PALABRAS LLAVES: Lógica. Composición. La derecha Justicia. Sistema legislativo.

\section{Aproximaçōes entre Lógica, Direito e Justiça}

A reflexão sobre as relações existentes entre a Lógica e o Direito faz as vezes de "um olhar sobre" o fato de estarmos reunidos em torno dessas duas matérias do conhecimento, que se nos apresentam como tão próximas e, ao mesmo tempo, distantes uma da outra. Por essa razão é que o tema a respcito do qual nos propusemos a discorrer busca a essencialidade das relações que se pode estabelecer entre a Lógica e o Direito: por "essencialidade", entenda-se a possivel intimidade, indissociabilidade e cumplicidade conceitual, na estreiteza dos laços comuns entre as acepções dominantes de verdade e de justiça no pensamento ocidental.

Portanto, ao empregarmos o vocábulo "essencialidade", não estamos aventando qualquer conotação de índole metafísica; mas sim referindonos a um cerne comum, que mais que superposição, é uma espécie mesma de genuína interseção entre as duas matérias, em sua maior proximidade. Aí, nesse núcleo, pode residir um caráter de unidade entre os dois saberes.

Admitamos que o marco teórico para uma origem comum entre a Lógica e o Direito esteja na Antiguidade, mais especificamente nas questões sobre a "busca da verdade", que é também uma das verves para toda a Filosofia. 
A idéia de justiça, já na Antiguidade, pressupõe a distinçâo entre o verdadeiro e o falso; o que é também alvo das atenções da Lógica, mormente no Classicismo. Ao mesmo tempo, a liberdade argumentativa e a indole persuasiva do caráter advocatício na defesa dos interesses, gera o desenvolvimento do Direito como uma arte de inventividade retórica. Especialmente a partir do período moderno, como sabido, as matérias do conhecimento - aí incluídas as lógicas aplicadas aos temas jurídicos desdobram-se em bifurcações e outras ramificações que, de certo modo, redundam em seu próprio desenvolvimento, na medida em que significam aprofundamento e especialização.

No caso jurídico, as hermenêuticas sociológicas e historicistas, que desempenharam papéis fundamentais para a garantia das liberdades democráticas no Estado Moderno de Direito, carrearam cada vez mais para o interior do discurso jurídico elementos dialéticos, difusos, visando transportar mais vivamente a realidade dos clamores culturais de um sujeito de direitos cujo conceito retratava um novo tempo na história social e política. Nesse momento, em um certo sentido, pode-se dizer que configuravam como incompativeis alguns pressupostos e princípios hirtos das logicizaçôes de talhe tradicional, em face das intensas transformações que alteravam a organização da sociedade. Em outros aspectos, porém, a Lógica Jurídica, já bem desenvolvida em sua autonomia didática e científica, continuava a fornecer suportes de verdade e segurança na concatenação dos argumentos por meio dos quais aflorava grande parte dos direitos pleiteados pelas gentes.

Mais ainda, as intensas modificações ocorridas na organização social no início do século passado e início deste, impulsionaram o aparecimento de novas relações jurídicas que, em última instância, projetaram modificações sobre a composição dos ordenamentos jurídicos, assim entendido o modelo pelo qual se estruturam as leis e os mecanismos funcionais do contexto mais amplo do Direito; e não apenas os raciocínios aplicáveis aos casos particulares.

Desse modo, nesta primeira aproximação, podemos considerar a viabilidade do estabelecimento de relaçóes entre i) a Lógica e os conceitos filosóficos que subjazem as idéias de justiça; ii) a Lógica enquanto raciocínio (dedutivo e indutivo), no sentido de inferências válidas aplicáveis a relações jurídicas fáticas, individuais e coletivas, nos variados ramos do Direito; e iii) a Lógica e a Teoria dos Ordenamentos Jurídicos, particularmente no que diz respeito à sua estrutura, mobilidade e modelos. É a este último tópico que vamos nos ater no presente estudo, a partir da próxima seção deste texto. 


\section{Projeções sobre a composição dos ordenamentos jurídicos}

Desde que Carnelutti reinterpretou a teoria kelseniana do ordenamento jurídico, fazendo-o a partir de todos os verbos - ações contidos nas normas processuais; e, na esteira de Carnelutti, Bobbio formulou a sua teoria do ordenamento a partir da trilogia composta pelos conceitos de unidade, coerência e completude, houve uma substanciosa alteração em várias composições do ordenamento das leis em diversos países do Ocidente.

A base sobre a qual se assentam essas modificações continua sendo, de uma maneira geral, a concepção kelseniana do ordenamento do Direito, à qual a Lógica Clássica oferece respostas compatíveis e bem acabadas. Examinaremos a seguir, em rápidas pinceladas, aspectos de algumas configurações recentes dos ordenamentos jurídicos, refletindo sobre as suas possibilidades de investigação pela Lógica, em especial pelas Lógicas Heterodoxas. Vejamos então alguns exemplos dessas configurações, deixando claro que esta não é uma abordagem exaustiva; mas preliminar, quanto à enumeração e quanto ao aprofundamento da matéria. Como ilustram os sub-títulos desta comunicação, estaremos fazendo "aproximações" e "projeções".

A multifacetação das relações juridicas, em decorrência da complexidade social, conforme mencionamos anteriormente, tem instaurado em vários ordenamentos, com maior ou menor envergadura e expressividade, a chamada teoria dos micro-sistemas, que consiste basicamente no seguinte: no âmbito maior do ordenamento jurídico constituído, passam a existir e a funcionar sub-sistemas em segmentos menores, regidos por leis e juízos próprios, embora consoantes com o ordenamento geral no qual se inserem. Assim sendo, nos micro-sistemas pode-se verificar uma certa autonomia, embora esta seja interdependente e interativa com o ordenamento geral. São exemplos de tendências micro-sistêmicas, em nosso país, os direitos do consumidor, a tutela jurídica ambientalista, o biodireito, o direito imobiliário, o direito socictário, a criação de juizados especiais cíveis e criminais e, dentre outros, a criação de jurisdições para determinadas especialidades, como, i.g., na Justiça Federal de Curitiba, as varas específicas para direito financeiro e previdenciário.

A característica principal desse fenômeno é que, se na hierarquia clássica kelseniana, os códigos preponderavam teórica e praticamente sobre as leis menores (dedução); atualmente ocorre que, em face das necessidades de 
especialização e das novas exigências sociais, as leis especificas que regem os micro-sistemas têm uma aplicação muito mais imediata e pronta (indução) do que os códigos, que passam a servir, muitas vezes, de modo subsidiário. Evidentemente, a jurisprudência assume funções cada vez mais relevantes diante dessas transformações. Ao nosso ver, a despeito do surgimento de micro-sistemas jurídicos e da especialização que eles ensejam, a codicização no Direito brasileiro é responsável pelo equilíbrio do ordenamento jurídico como um todo, tal como se apresenta. Seria extremamente argüível, sob o ponto de vista lógico, descodificar alguns segmentos do ordenamento, mantendo a codificação em outros, em detrimento do caráter de unidade do sistema.

Tais alterações, na verdade, são muito mais de ordem funcional e prática, porque da prática despontam. Todavia, continua prevalecendo o "desenho" da pirâmide kelseniana, pano de fundo sobre o qual pode se assentar a dinâmica dos micro-sistemas, acima descrita.

No caso brasileiro, houve uma interessante celeuma a respeito do direito de família: sendo essa matéria regida, em grande parte das ações ajuizadas, pela lei do divórcio e pela lei da união estável; mas sendo igualmente matéria disciplinada pelo Código Civil, discutia-se se o direito familial seria ou não um micro-sistema jurídico. Com a promulgação do novo Código Civil, em breve essa e outras questões hão de ser atendidas, posto que matérias jurídicas estarão submetidas a considerável atualização. Todavia, o debate acerca das especializações das leis em face dos avanços sociais e tecnológicos prossegue, com interesses sob o ponto de vista da Lógica e da Metodologia Jurídicas.

Há modificações também no âmbito processual, como exemplificam as tutelas antecipatórias e as ações monitórias, que invertem no tempo alguns procedimentos judiciais, ocasionando assim movimentos diferenciados no interior do ordenamento do Direito.

Cite-se também os chamados direitos de última geração, como v.g. os direitos difusos e transindividuais, caracterizados por um renovado entendimento acerca dos sujeitos que, mais que ensejam - urgem! - por lógicas que se lhes apresentem como compatíveis.

Diga-se o mesmo a respeito dos movimentos de constitucionalização do Direito Civil, como ocorre na Itália e nos Estados Unidos da América, em cuja ordenação a aplicação da lei aos casos concretos se faz diretamente à luz da norma constitucional, sem o intermédio dos códigos.

Podemos destacar ainda, no contexto da teoria dos ordenamentos jurídicos 
(que por sua vez, é um dos capítulos da Teoria Geral do Direito), outros "desenhos", como o sistema de cláusulas gerais e cláusulas móveis, que pressupõe "movimentos", "deslocamentos", "justaposições" e "intrerseções" das disposições normativas no momento da aplicação, visando a adequação a cada caso, de acordo com as concepções de justiça dominantes, diferindo, desse modo, da nomoestática e da nomodinâmica sistematizadas por Kelsen.

São interessantes também as teorias autopoiéticas do direito, que interpretam os ordenamentos a partir da sua auto-recursividade lógica: o sistema jurídico cria, ele mesmo, instâncias superiores de si próprio, às quais recorre. Nesse diapasão, há várias formulações de teorias jurídicas sistêmicas das quais, até o presente momento, não se tem notícias sobre publicações a respeito de estudos que as analisem sob o ponto de vista específico da Lógica.

Idem quanto às teorias tópicas, que fazem a leitura da composição dos ordenamentos a partir de seus aspectos contraditórios e antinômicos: o "pensar tópico" é um "pensar por problemas" e, nesse sentido, é um método considerado oposto às concepções funcionalistas e sistêmicas.

Voltando ao caso brasileiro, se o fenômeno dos micro-sistemas no ordenamento jurídico descreve uma alegoria que poderíamos dizer "circular e em direção à profundidade", cabe considerar que há também outras inovações concomitantes, que poderíamos metaforicamente denominar "traçados horizontais" no ordenamento, como as migrações, fusões e difusões de institutos jurídicos, não somente da esfera pública para a privada e vice-versa; mas também entre os ramos do Direito entre si, provocando movimentações na estrutura originalmente concebida, como bem exemplifica a Responsabilidade Civil.

\section{Conclusão}

Diante das transformações suscitadas no Direito, só não cabe a indiferença $e$, na condição de intelectuais efetivamente engajados com as questões do nosso tempo, urge colocarmo-nos desde logo a trabalho. Especialmente porque, tendo ciência dos avanços da Lógica na atualidade, pode-se não apenas vislumbrar soluções práticas para os casos concretos; mas ressalta-se também a importância das teorias e fundamentações filosóficas renovadas.

O desenvolvimento das especialidades no Direito faz ressurgir o interesse pela Teoria Geral, como dois polos que se revigoram reciprocamente, pela compreensão cada vez mais profunda de que as partes não 
subsistem sem o todo e vice-versa; tema no qual a Lógica também desempenha um preponderante papel.

Deste breve ensaio, ao comentarmos genericamente aspectos de alguns modelos dos ordenamentos jurídicos, tais como os micro-sistemas, a tópica, a teoria autopoiética e outras fações sistêmicas; e também as tendências consitucionalizantes do Direito Civil, podemos inferir como a Lógica pode aclarar as leituras dessas modelagens e as conseqüentes interpretações sobre o seu desenho, em termos de equilíbrio e proporcionalidade no ordenamento; bem como oferecer sugestōes, à guisa de projeções ou mesmo de soluções pelas quais clamam várias questões do Direito em nosso tempo.

Quando nos referimos ao ordenamento jurídico, estamos pensando sobre a sua estrutura, sobre a forma que o modela, abstraída dos conteúdos das normas de direito material e processual. Na verdade, a visualização dessa organização, bem como das dinâmicas que a compõem, pode ser sobejamente acrescida, ao se ter em conta que o estudo das estruturas sua composição, relações, equilíbrio, projeções, tendências e interpretações - é matéria bastante avançada no domínio da Lógica. Esse é uma dado a ser seriamente considerado, particularmente quando se busca novos aportes para a inteligência juridica.

Mesmo no Direito posto - assim entendido o ordenamento jurídico em vigor em nosso país - há diversos assuntos a serem tratados pela Lógi$\mathrm{ca}, \mathrm{como}$, por exemplo, a elucidação de parâmetros para as gradaçôes e eqüidade expressamente determinadas pelo legislador do novo Código Civil, no que concerne à indenização dos danos causados à pessoa; além das antinomias, lacunas e eventuais contradições existentes entre disposições normativas e jurisprudenciais, em vários ramos do Direito; e também aspectos do Direito Internacional Público e Privado, dentre outros.

Por derradeiro, gostaria de dizer que esta exposição pode ser entendida de duas maneiras: retrospectiva, sobre a essencialidade de dois saberes cujos primórdios podem ser tão antigos quanto a razăo; e prospectiva, para fazer dessa essencialidade um futuro que começa a se esboçar.

\section{BIBLIOGRAFIA}

ANDRADE, M. A. Domingues de. Teoria geral da relação jurídica. (vols. I e II). 7. Reimpressão. Coimbra: Almedina, 1992.

BADIOU, A. Para uma nova teoria do sujeito (trad. de Emerson Xavier da Silva e Gilda Sodré), in Conferências Brasileiras. Rio de Janeiro: Relume Dumará, 1994. 
BLEICHER, Josef. Hermenêutica contemporânea. Lisboa: Edições 70, 1980. BOBBIO, Norberto. Studi sulla teoria generale del diritto. Torino: Giappicheli, 1995.

Teoria do ordenamento juridico. (Apres. Tércio Sampaio de Ferraz Junior; Trad. de M. Celeste C. L. Santos). 6. ed., Brasília: UNB, 1995.

BULYGIN, E. Norma jurídica y analisis logico. Madrid: Centro de Estudos Constitucionales, 1988.

CANARIS, C. W. Pensamento sistemático e conceito de sistema ciência do diretto. Lisboa: Fundação Calouste Gulbertkian, 1989.

CARBONNIER, J. Flexible droit - pour une sociologie du droit sans rigueur. Paris: LGDJ, 1992.

CARVALHO, O. A teoria geral da relação juridica - seu sentido e limites. 2. ed., Coimbra: Centelha, 1981.

CASO, R. C. El principio de la buena fe como fundamento ético de las relaciones juridicas. (in Etica y Derecho). Buenos Aires: Fundación Casa Ricardo Balbin, 1998.

CORDEIRO, A. M. A boa fé nos finais do século XX. Lisboa: Revista da Ordem dos Advogados, 1996.

CUNHA, P. F. Introdução à teoria do direito. Porto: Rés, 1995.

Princípios de direito (introdução à filosofia metodologia jurídicas).

Porto: Rés, 1995.

DALLEGRAVE NETO, J. A. O sistema jurídico herdado do positivismo científico e os códigos civis novecentistas. Revista do Instituto dos Advogados do Paraná, n"26, Curitiba: IAP, 1996.

EWALD, François. Le droit du droit in Archives philosophie du droit (Le systéme juridique). t. 31, Paris: Sirey, 1986.

FRANCA L. Hermenêutica jurídica. 3. ed., São Paulo: Saraiva, 1994.

FRIEDMAN, W. Théorie générale du droit. vol. VI (Bibliotéque de philosophie du droit). 4. ed., Paris: Librairie Générale de droit et de jurisprudence, 1965.

GOMES, O. Transformações gerais do direito e das obrigações. 2. ed., São Paulo: Editora Revista dos Tribunais, 1980.

HART, H. L. A. O conceito de direito (questões persistentes). Lisboa: Fundação Calouste Gulbenkian, 1986.

KELSEN, H. Teoria geral das normas. (trad. José Florentino Duarte). Porto Alegre: Sergio Antonio Fabris Editor, 1986.

LAMEGO, J. Hermêutica e jurisprudência (análise de uma recepção). Lisboa: Fragmentos, 1989.

LARENZ, K. Metodología de la ciencia del derecho. Barcelona: Ariel, 1966. MELLO, M. B. Teoria do fato jurídico: plano de validade. São Paulo: Saraiva, 1995.

MOTA PINTO, C. A. Teoria geral do direito civil. 3. ed., 9. reimp., Coimbra: Coimbra Editora Limitada, 1994. 
MÜLLER, F. Discours de la méthode juridique. Paris: Leviathan/Presses Universitaires de France, 1996.

NEIPP, V. Causalidad juridica y representación. Colección Breviários de Derecho, $\mathrm{n}^{\circ}$ 53, Buenos Aires: Ediciones Juridicas Europa-América, 1962.

PASQUIER, C. Introduction à la théorie générale et à la philosophie du droit. 5. ed., Paris: Delachaux et Niestlé Editeurs, 1979.

PERLINGIERI, P. Perfis do direito civil: introdução ao direito civil constitucional. Rio de Janeiro: Renovar, 1997.

PRIEUR, M. Le principe de la participation des citoyens. (in Droit de Penvironnement). Paris: Dalloz, 1984.

PUCEIRO, É. Z. Teoria del derecho. (una introducción crítica). Buenos Aires: Depalma, 1987.

REALE, M. Visão geral do projeto de Código Civil.

ROPPO, E. O contrato. Coimbra: Almedina, 1988.

ROTTLEUTHNER, H. Les métaphores biologiques dans la pensée juridique. in Archives de philosophie du droit, t. 31 (Le systéme juridique). Paris: Sirey, 1986.

. Un cas récent: l'autopoiésis dans le droit. (Le systéme juridique en tant que système autopoiétique), in Arquives de philosophie du droit, t. 31, (Le systéme juridique). Paris: Sirey, 1986.

TEUBNER, G. O direito como sistema autopoiético. Lisboa: Fundação Calouste Gulbenkian, 1989.

TUNC, A. La responsabilité civile. Paris: Económica, 1981.

VARELA, A. Das obrigações em geral. Vol. I, 8. ed., Coimbra: Almedina, 1994

VASCONCELOS, A. Teoria geral do direito. (Teoria da norma jurídica). 3. ed., São Paulo: Malheiros, 1993.

VERNENGO, R. J. Curso de teoría general del derecho. Buenos Aires: Cooperadora de Derecho y Ciencias Sociales, 1976.

VIEHWEG, T. Tópica e jurisprudência. (Trad. de Tércio Sampaio de Ferraz Junior). Brasília: Departamento de Imprensa Nacional, 1979.

WIEACKER, F. História do direito privado modemo. 2. ed., Lisboa: Calouste Gulbenkian, 1993. 